\title{
Tatianos
}

\section{Oratio ad Graecos / Rede an die Griechen}

\author{
Hrsg. u. neu übers. v. Jörg Trelenberg
}

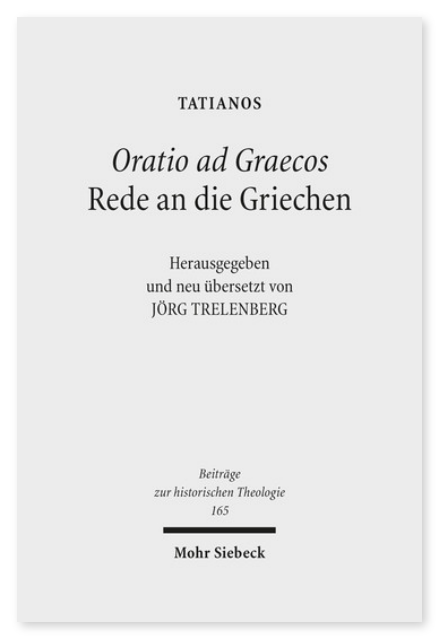

2012. X, 308 Seiten. BHTh 165

ISBN 978-3-16-151875-1

DOI 10.1628/978-3-16-151875-1

eBook PDF $149,00 €$

ISBN 978-3-16-150939-1

Leinen $149,00 €$
Tatians O ratio ad Graecos ist eine kulturhistorisch und theologisch höchst wertvolle Schrift des zweiten nachchristlichen Jahrhunderts. Sie erleichtert das Verständnis eines Christentums, das zunehmend auch die höheren sozialen Schichten ergreift und mit wachsendem Selbstbewusstsein nicht mehr bereit ist, die pagane Kulturhoheit in der griechisch-römischen Welt zu akzeptieren. Der Autor versteht sich als die Stimme einer äußerlich unterdrückten, aber innerlich stolzen religiösen Minderheit, die sich von deklassierenden Vorurteilen mehr und mehr emanzipieren und gesellschaftliche Erniedrigung nicht länger ertragen will. Die Oratio ad Graecos ist ein beredtes Zeugnis für eine im aufstrebenden Christentum sich verstärkende Stimmung und Neigung, allmählich den »Kampf der Kulturen« zu probieren und mit allen Konsequenzen aufzunehmen.

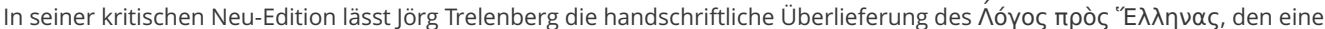
hochspekulative Textemendation in der Vergangenheit stark verfremdet hatte, wieder stärker zur Geltung kommen. Seine neue deutsche Übersetzung ersetzt die verdienstvolle, aber nach nunmehr 100 Jahren veraltete Version in der BKV durch eine moderne, den fortgeschrittenen Forschungsstand berücksichtigende Fassung. Zahlreiche Sacherklärungen bieten dem modernen Leser Hilfen für das Verständnis, die ausführliche Werkeinleitung bündelt die gelehrte Diskussion der letzten anderthalb Jahrhunderte. Einen Abschluss bildet die Erörterung von Spezialproblemen, beispielsweise das Verhältnis Tatians zu Justin, die Frage nach Tatians gnostischer Häresie oder auch das Problem der Gattung dieses ungewöhnlichen und in seiner Art einmaligen Werkes.

Tatianos Keine aktuellen Daten verfügbar.

Jörg Trelenberg Geboren 1965; Studium der evangelischen Theologie sowie der lateinischen und griechischen Philologie in Münster; Oberstudienrat in Hemer; 2003 Promotion; 2007 Habilitation.

Jetzt bestellen:

https://mohrsiebeck.com/buch/oratio-ad-graecos-rede-an-die-griechen-9783161518751?no_cache=1 order@mohrsiebeck.com

Telefon: +49 (0)7071-923-17

Telefax: +49 (0)7071-51104 